Int. J. Electrochem. Sci., 14 (2019) 7925 - 7936

\title{
Preparation and Electrochemical Performance of Spherical Mesophase Soft Carbon Materials Composite Anodes for Lithium-ion Batteries
}

\author{
Hao Lin ${ }^{1}$, Qinghai Zhao ${ }^{2}$, Hongxin Zhang ${ }^{1,2, *}$ \\ ${ }^{1}$ School of Mechanical and Electrical Engineering, Qingdao University, Qingdao, 266071, China \\ ${ }^{2}$ Power Integration and Energy Storage System Engineering and Technology Center, Qingdao \\ University, Qingdao, 266071, China \\ "E-mail: qduzhx@126.com
}

doi: $10.20964 / 2019.08 .17$

Received: 25 Janaury 2019 / Accepted: 27 May 2019 / Published: 30 June 2019

\begin{abstract}
It is imperative to develop lithium battery anode materials with high power performance. In this paper, by improving the preparation process, a novel micro-nano composite structure spherical mesophase soft carbon material was developed as the anode material of a lithium-ion battery. The structure and surface morphology were observed by SEM and XRD. The material was assembled into a button battery and a power battery for performance testing and safety testing. The experimental results indicate that the prepared soft carbon material has excellent surface properties and a uniform shape distribution. The first coulombic efficiency of the button battery is $87.5 \%$. The charging capacity and discharging capacity ratios at $2 \mathrm{C} / 1 \mathrm{C}$ are $84.8 \%$ and $85.9 \%$, respectively. The capacity retention rate after 50 cycles at $0.5 \mathrm{C}$ is 99.9\%. The discharge capacity of the battery decreases with increasing discharge ratio. After 500 cycles at $0.5 \mathrm{C}, 93.96 \%$ of the capacity is maintained. In low-temperature testing at $-20^{\circ} \mathrm{C}$, the discharge rate is $98.94 \%$, while in high-temperature testing at $60^{\circ} \mathrm{C}$, the discharge rate is $99.74 \%$. The battery does not catch fire under needle punching, extrusion or overcharging. Therefore, the new soft carbon battery has excellent working performance and can be used as a new energy storage battery.
\end{abstract}

Keywords: Lithium ion battery, Soft carbon anode, Cyclic performance, Working performance

\section{FULL TEXT}

(C) 2019 The Authors. Published by ESG (www.electrochemsci.org). This article is an open access article distributed under the terms and conditions of the Creative Commons Attribution license (http://creativecommons.org/licenses/by/4.0/). 